\title{
Physical Activity in Our Modern World: An Evolutionary Necessity
}

\author{
Peter Lembessis $^{1 *}$, Stamatis Mourtakos ${ }^{1,2}$ and Anastassios Philippou ${ }^{1}$ \\ ${ }^{1}$ National and Kapodistrian University of Athens, Medical School, Department of Physiology, Greece \\ ${ }^{2}$ Harokopio University of Athens, Department of Nutrition and Dietetics, Greece
}

${ }^{\star}$ Corresponding author: Peter Lembessis, Department of Physiology, Medical School, National and Kapodistrian University of Athens, 75 Micras Asias, Goudi-Athens, 115 27, Greece; Tel: +(30 210) 7462506; Fax: +(30 210) 7462571; E-mail: panlemb@med.uoa.gr

Received: April 28, 2021; Accepted: May 04, 2021; Published: May 15, 2021

In our modern world obesity is a causal factor in numerous metabolic and endocrine disorders including heart disease, nonalcoholic fatty liver disease (NAFLD), type 2 diabetes mellitus (T2DM), bone and joint disorders and some types of cancer [1]. According to the World Health Organization in 2016, globally more than 1.9 billion adults were overweight and of these over 650 million were obese [2]. Childhood obesity is a more disturbing trend; in 2019 thirty eight million children under the age of 5 were overweight or obese and in 2016 over 340 million children and adolescents aged 5-19 were overweight or obese [3]. Obesity is not a cosmetic issue but rather an affliction that places a tremendous burden to quality of life on individuals and health care systems. It is not without exaggeration to say that obesity due to physical inactivity is the biggest public health problem of the $21^{\text {st }}$ century [4]. However, obesity is preventable and reversible and for interpreting the obesity pandemic afflicting modern societies we need to understand our evolutionary history and examine the environmental, physical, and physiological conditions that impelled our ancestral gorilla-chimpanzee lineageto shift from a sedentary, plant and fruit diet existence to a foraging, meat eating, hunter-gatherer existence some 2.5 million years ago [5].

The transition of our ancestral lineage from the gorilla-chimpanzee line to hunter gatherer necessitated changes in diet, metabolism and physiology that are conducive for high levels of physical activity for survival. Although the environmental, physical, and physiological conditions have changed, our physiology remains genetically adapted for a nomadic forager, hunter gatherer life style [6,7]. Our physiology adapted to storing lipids and carbohydrates as fuels to cope with the uncertainties of food availability in our past. This may have been a survival advantage 2.5 million years ago, but in our modern world it is a liability that leads to increased morbidity and mortality due to increased circulating triglycerides, cholesterol, blood pressure, T2D, NAFLD, Alzheimer's disease, cardiovascular disease (CVD), and several types of cancer [8,9]. For most of our evolutionary history, as conditions changed so did our physiology. Our lungs, brain, muscles, blood vessels and all our organs and physiological organ systems have evolved to support a high activity level demanded for survival and our bodies have retained this adaptation to the present day. However, we no longer have to forage 15-20 kilometers per day, nor do we have to fend off predators or perform exhaustive farming practices to necessitate high energy diets. In evolutionary terms, the modern norms of an inactive lifestyle and a diet based on an excess of energydense, nutrient-deficient, foods such animal products, processed foods, alcohol, sugar and sugar derivatives are not conducive for the purpose for which we evolved.

To prevent or reverse the obesity epidemic and minimize our proclivity to obesity and the subsequent metabolic disorders we need to modify our diet and increase our levels of physical activity. We need to exercise. Our physiology is a dynamic product of evolution that adjusts to changes in living conditions. Regular exercise reduces chronic inflammation which constitutes risk factor for CVD, it reduces insulin resistance which is a harbinger for T2D and helps to shuttle glucose into muscle glycogen stores instead of fat, thus helping reduce triglycerides from the circulation [10]. Additionally, it lowers resting levels of testosterone, estrogen and progesterone, which may explain the reduced rate of reproductive cancers among adults who exercise regularly, improves the effectiveness of immune function, which helps stave off infection especially as we age, and may blunt the morning rise of the stress hormone cortisol [11]. Other than maintaining health, physical activity contributes to healthy aging by reducing the accumulation of senescent cells and the of secretion of a complex mixture of different inflammatory cytokines, chemokines, growth factors and proteases such as IL1a, IL1b, IL6, IL8 and metalloproteinases (MP-1, MP-3) that contribute to the aging process [12]. Also, evidence supports an association between exposure to regular exercise and reduced risk for the development of several cancers that might improve clinical outcomes following a diagnosis of primary disease $[7,13]$.

In order to prevent or reverse the obesity pandemic afflicting modern societies the WHO recommends adults undertake at least 150 min moderate or 75 min vigorous intensity physical activity per week, conduct muscle strengthening activities twice a week, and minimize time spent being sedentary [14]. In an effort to counteract the risks of a sedentary lifestyle the "Exercise is Medicine initiative" in collaboration with the American College of Sports Medicine and American Medical Association was introduced in 2007 to advance the implementation of evidence-based strategies and incorporate exercise as part of a standard treatment for conditions related to sedentary lifestyle such as T2D, CVD, 
and obesity. It calls for the assessment of the every patient's physical activity program and prescribing a regimen tailored to each individual's condition and needs. The implementation of this initiative may change patient behaviour, lighten the burden placed on the quality of life and healthcare systems. The benefits of a structured, regular physical activity regimen for health and disease prevention are unequivocal. Natural selection has tailored our bodies for movement and our physiology has retained the metabolic hunter-gatherer characteristics that do not conform to the sedentary way of life of modern societies. Our contemporary lifestyle and dietary habits conflict with our evolutionary outcome. A quote attributed to Hippocrates (460-370 BC) states "If we could give every individual the right amount of nourishment and exercise, neither too much nor too little, we would have found the safest way to health". A more recent comment by Manini TM (2015) in the JAMA-Internal Medicine testifies that "there is no single medication treatment that can influence as many organ systems in a positive manner as can physical activity" [15].

\section{Author Contributions}

Peter Lembessis: Conceptualization of topic, literature search, writing of original draft.

Anastassios Philippou: Review \& editing, literature search.

Stamatis Mourtakos: Literature search on nutrition and dietetics, review and editing of draft.

\section{References}

1. Mantovani A, Allavena P, Sica A, Balkwill F (2008) Cancer-related inflammation. Nature 454: 436-444.
2. WHO (2020) Obesity and overweight.

3. Saklayen MG (2018) The Global Epidemic of the Metabolic Syndrome. Curr Hypertens Rep 20: 12. [crossref]

4. Cowan RE (2016) Exercise Is Medicine Initiative: Physical Activity as a Vital Sign and Prescription in Adult Rehabilitation Practice. Arch Phys Med Rehabil 97: S232-237. [crossref]

5. Sarich VM, Wilson A C (1967) Immunological time scale for hominid evolution. Science 158: 1200-1203.

6. Hambrecht R, Gielen S (2005) Essay: Hunter-gatherer to sedentary lifestyle. Lancet 366: S60-61. [crossref]

7. Koelwyn GJ, Quail DF, Zhang X, White RM, Jones LW (2017) Exercise-dependent regulation of the tumour microenvironment. Nat Rev Cancer 17: 620-632. [crossref]

8. Freese J, Klement RJ, Ruiz-Núñez B, Schwarz S, Lötzerich H (2017) The sedentary (r) evolution: Have we lost our metabolic flexibility? F1000Res 6: 1787. [crossref]

9. Rezende LFM, Sá TH, Markozannes G, Rey-López JP, Lee IM, et al. (2018) Physical activity and cancer: an umbrella review of the literature including 22 major anatomical sites and 770000 cancer cases. Br J Sports Med 52: 826-833. [crossref]

10. Handschin C, Spiegelman BM (2008) The role of exercise and PGCla in inflammation and chronic disease. Nature 454: 463-469. [crossref]

11. Kelly RS, Kelly MP, Kelly P (2020) Metabolomics, physical activity, exercise and health: A review of the current evidence. Biochim Biophys Acta Mol Basis Dis 1866: 165936. [crossref]

12. Schafer MJ, White TA, Evans G, Tonne JM, Verzosa GC, et al. (2016) Exercise Prevents Diet-Induced Cellular Senescence in Adipose Tissue. Diabetes 65: 1606-15. [crossref].

13. Ruiz-Casado A, Martín-Ruiz A, Pérez LM, Provencio M, Fiuza-Luces C, et al. (2017) Exercise and the Hallmarks of Cancer. Trends Cancer 3: 423-441. [crossref]

14. Sallis JF, Bull F, Guthold R, Heath GW, Inoue S, et al. (2016) Progress in physical activity over the Olympic quadrennium. Lancet 388: 1325-1336. [crossref]

15. Manini TM (2015) Using Physical Activity to Gain the Most Public Health Bang for the Buck. JAMA Intern Med 176: 968-9. [crossref] 